\title{
Effect of acidulated phosphate fluoride application on microhardness of glass ionomer cement
}

\author{
Mohammad Azrul Izzudin*, Elin Karlina*, Ratna Indriyanti** \\ *Department of Dental Material Science and Technology Faculty of Dentistry Universitas \\ Padjadjaran, Indonesia \\ **Department of Pedodontics Faculty of Dentistry Universitas Padjadjaran, Indonesia
}

\section{ABSTRACT}

Introduction: Acidulated phosphate fluoride (APF) gels are commonly used as preventive caries materials in paediatric dentistry while glass ionomer cements (GICs) are widely used as a restorative material. The purpose of this study was to determine the effect of acidulated phosphate fluoride application towards the microhardness of GIC. Methods: This study was an experimental laboratory study where ten specimens were prepared from high viscosity GIC, which was Fuji IX. Specimens were stored in $50 \mathrm{ml}$ distilled water at first 24 hours at $37^{\circ} \mathrm{C}$, and then specimens were divided into fluoride group which was immersed in $25 \mathrm{ml}$ of $1.23 \%$ APF gel and control group which was stored $25 \mathrm{ml}$ distilled water for 24 hours at $37^{\circ} \mathrm{C}$. The Micromet II Microhardness Tester, Buehler, IL, USA that was standardised for Vickers hardness test was used to test the specimens at 100-gram load. Data were analysed using the t-test comparison test. Results: The level of microhardness of the fluoride group (14.34) was much lower compared to the control group (43.21) with a highly significant difference $(p<0.01)$. Conclusion: The application of $1.23 \%$ APF gel on high viscosity GIC reduces the microhardness level compared to the control group.

Keywords: Glass ionomer cement, acidulated phosphate fluoride, topical fluoride, microhardness.

\section{INTRODUCTION}

Dental caries has been one of the most prevalent diseases, and yet there are considerable variation in its occurrence between the countries, regions, social, and ethnic groups. ${ }^{1}$ Dental caries is a disease often found in children's teeth. Over $40 \%$ to $50 \%$ of 5 years old children ( 3 out of 4 preschool children) still have caries with a long term impact on their oral health throughout life..$^{1-3}$

Dental caries is the disease that must be treated or prevent before it has become worse.
One type of preventive therapy is a topical fluoride treatment. Acidulated phosphate fluoride (APF) gels are one example of topical fluoride that is widely used. The APF gels contain phosphoric acid which etches the enamel, enhancing fluoride uptake. However, patients with glass ionomer restorations and receiving APF treatments could be at risk of increasing the surface roughness of the materials due to their vulnerability to the acidic nature of the APF gel. This condition is a crucial feature regarding avoidance of plaque retention. ${ }^{4}$ 
The changes in surface texture may affect the microhardness of the glass ionomer materials. It is also known that the prolonged setting reaction, dehydration or hydration of glass ionomers after the initial setting may influence their surface hardness and wear resistance. ${ }^{4}$ The purpose of this research is to know effects of acidulated phosphate fluoride application towards the microhardness of glass ionomer cement.

\section{METHODS}

The type of this research is a laboratory experimental study, carried out to see the effect of acidulated phosphate fluoride towards the microhardness of glass ionomer cement. It consists of laboratory test and data analysis. The research specimens were using high viscosity glass ionomer cement. Ten pellets of specimens were made from high viscosity glass ionomer cements.

Certain considerations that included in this research are as follows: The sample preparations were in the same dimension which $6 \mathrm{~mm}$ diameter and $4 \mathrm{~mm}$ thick using disc shape customized mold, the experiment was conducted from the same experimental tools, mixing the specimens was depending on the manufacturer's instructions, the specimens were made into 2 groups as follow: group 1 fluoride group and group 2: control group that contain fifth specimens each.

The data were gathered, analyzed statistically using T-test comparison test and presented in table and bar chart form.

\section{RESULTS}

Laboratory results showed that the mean of Vickers Hardness Number (VHN) of 10 samples consisting of 5 samples of the fluoride and 5 samples of the control group is presented in Table 3 as follows.
From the table above, it is indicated that the average level of microhardness of fluoride group (14.34) is lower than the level of microhardness of control group (43.21). The average value is presented in a bar chart 1 as follows.

Based on table 4 above, the results of homogeneity tests of variance using Levene's Test produced a $p$-value of 0.115 . This value is greater than 0.05 so that it can be concluded that the data in the two groups have a homogeneous variance. With this condition, then uses the comparison test on the top row (equal variances assumed) which is amounted to -40.860 with $\mathrm{p}$-value of

Table 1. Microhardness of GIC (Vicker's hardness number) of fluoride group and control group

\begin{tabular}{ccc}
\hline Number of sample & Fluoride & Control \\
\hline 1 & 13.00 & 43.66 \\
2 & 15.18 & 41.50 \\
3 & 14.70 & 42.10 \\
4 & 14.60 & 44.60 \\
5 & 14.20 & 44.20 \\
\hline Means VHN & 14.34 & 43.21 \\
\hline Standard Deviation & $\mathbf{0 . 8 2}$ & 1.35 \\
\hline
\end{tabular}

Figure 1. Average value of microhardness of glass ionomer cementin fluoride and control

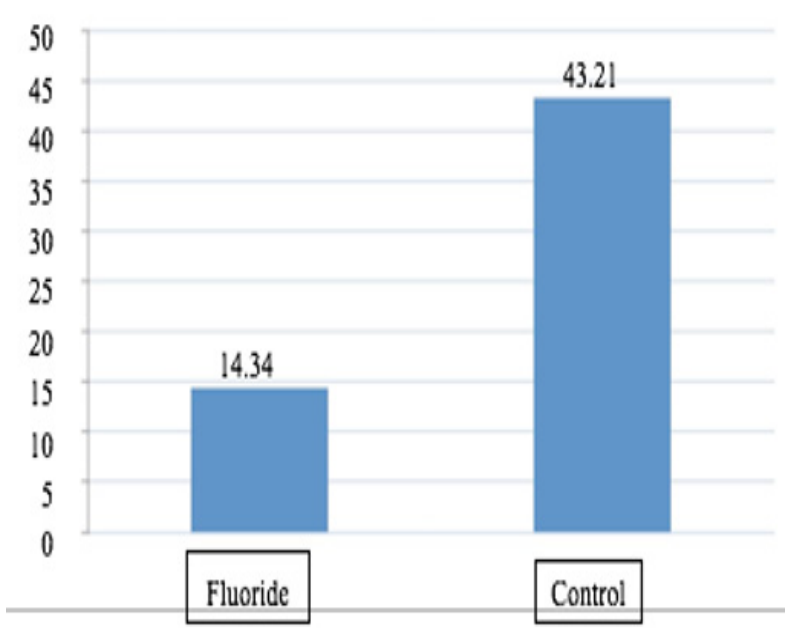

Table 2. Microhardness t-test comparison test result

\begin{tabular}{|c|c|c|c|c|c|c|c|}
\hline & & \multicolumn{2}{|c|}{$\begin{array}{c}\text { Levene's test of } \\
\text { equality of variance }\end{array}$} & \multicolumn{4}{|c|}{ T-test for equality of means } \\
\hline & & $\mathrm{F}$ & Sig. & $\mathrm{t}$ & df & Sig. (2-tailed) & Mean difference \\
\hline \multirow{2}{*}{ Microhardness } & Equal variances assumed & 3.119 & .115 & -40.860 & 8 & .000 & -28.87600 \\
\hline & Equal variances not assumed & & & -40.860 & 6.624 & .000 & -28.87600 \\
\hline
\end{tabular}


0.000 . Due to the p-value less than 0.01 then it can be concluded that the level of microhardness both groups shows a highly significant difference. Based on the results, it is known that the level of microhardness of fluoride group (14.34) is much lower than the level of microhardness of control group (43.21). Thus it can be concluded that the use of fluoride produce the level of microhardness is much lower than the control group, with a highly significant difference $(p<0.01)$.

\section{DISCUSSION}

Topical fluoride application in the form of $1.23 \%$ acidulated phosphate fluoride (APF), has become an establish preventive measure not only in children but also in general population. Topical fluoride such as APF gel can recharge the fluoride content of exhausted glass ionomer cement (GIC), thus converting into fluoride reservoir. However, there is concern as to the effects of acidic nature of APF on the surface properties of restoration material such as GIC. ${ }^{4}$ Although some studies have suggested that topical application of APF could restore fluoride level of glass ionomer cement ${ }^{5}$, the presence of both hydrofluoric and phosphoric acid in the APF could cause superficial structural damage to the glass ionomer. ${ }^{6}$ In addition, the $\mathrm{pH}$ of the acidulated phosphate fluoride is approximately 3 to 4 which can cause erosion of the cement due to the acid etching of the surface. ${ }^{7}$

Glass ionomer cements are clinically accepted as preventive restorative material because of their fluoride releasing properties besides their biocompatibility and clinical adhesive to enamel and dentin. Because they release fluoride ion, they are particularly useful where cariostatic action is needed. ${ }^{8}$ Surface hardness is defined as resistance of material to indentation of penetration and it's reflecting the resistance to abrasion of material surface. ${ }^{9}$ It is therefore an important parameter in evaluating restorative materials, especially those intended to restore Class V cavities where they become subjected to abrasive forces. ${ }^{6}$ Hardness measurements allow relative determination of this behavior.

Vickers's microhardness test used in this study is one of the available microhardness tests present nowadays. Beside Vickers hardness test, there are also Brinell, Knoop, and Rockwell hardness tests. Vicker and Brinell hardness tests employ the same principle of hardness testing, however in the Vickers hardness test, a squarebased pyramid indenter is used instead of a steel ball used in the Brinell hardness test. ${ }^{10}$ Vicker and Knoop tests are classified as microhardness test in comparison with Brinell and Rockwell test. Both of these tests employ loads less than $9.8 \mathrm{~N}$, and the results are small and limited to a depth of less than $19 \mu \mathrm{m}$. Hence they are capable of measuring the hardness in small region and thin objects. Vickers hardness test is suitable for measuring the hardness of brittle materials. Therefore, this test is suitable for testing the microhardness of glass ionomer cement since glass ionomer cements are brittle material. ${ }^{11} 1.23 \%$ APF gel was used in this study since this is the American Dental Association recommended specifications for professionally applied topical fluorides. So in this study, $1.23 \%$ APF gel applied for 24 hours produced significant reduction in the microhardness value in the experimental group with mean VHN value of 14.34 compared to the control group (43.21). One of the components in the APF gel is phosphoric acid which is well known as glass etchant that can cause erosion of enamel and restorative material. Several studies have shown that phosphoric acid significantly alter the structure morphology of various restorative material leading to changes the physical properties such as hardness, roughness and erosion resistance. ${ }^{12,13}$

Smith has shown in his journal that glass ionomer surface integrity is essentially destroyed after one minute of phosphoric acid etching and that individual particle dissociates from each other as the gel matrix dissolves. ${ }^{14}$ In this study, it is shown that the use of APF gel application reduces the microhardness of glass ionomer cement.

\section{CONCLUSION}

The use of acidulated phosphate fluoride application on glass ionomer cement produces much lower level of microhardness than the control group.

\section{REFERENCES}

1. Welbury R, Dunggal MS, Hosey MT. Pediatric dentistry. $3^{\text {rd }}$ ed. Oxford University Press. 
Michigan University. 2005

2. Finn SB. Clinical pedodontic. $4^{\text {th }}$ ed. W.B. Saunder Co. St. Louis. 2003.

3. Walmsley AD, Walsh TF, Burke FJT, Shortall ACC, Lumley PJ, Hayes-Hall R. Restorative dentistry, elsevier health sciences. 2007.

4. Salama FS, Elmallakh BF, Pedo C. Effect of apf application on the microhardness of lightactivated restorative material. J Sau Dent, 1996;8:81-6.

5. Ylp HK, Smales RJ. Fluoride release and uptake by aged resin-modified glass ionomers and apolyacid modified resin composite. Int Dent J. 1999 Aug;49(4):217-25.

6. Kula K, Nelson S, Kula T, Thompson V. In Vitro Effect of acidulated phosphate fluoride gel on the surface of composites with different filler particles. JProsthetDent.1986Aug;56(2):161-9.

7. Crisp S, Lewis BG, Wilson AD. Characterization of glass ionomer. cements. a study of erosion and water absorption in both neutral and acidic media. J Dent. 1980 Mar;8(1):68-74.

8. Gill NC, Pathak A. Comperative evaluation of the effect of topical fluoride on the microhardness of various restorative material:
An in vitro study. J Indian Soc Pedod Prev Dent. 2010 Jul-Sep;28(3):193-9.

9. O'Brien WJ. Physical properties in dental material and their selection $3^{\text {rd }}$ Ed. Illinois, Quintessenc: Publishing CO. 2002.

10. Anusavice KJ. Philips' science of dental materials $11^{\text {th }}$ ed. St. Louis. Missouri;Elsevier Inc. 2003.

11. Nadia I, Faisal B, Saqib R, Taslem H. Comparison of conventional glass ionomer cement and compomer in class ii restoration in primary molar: six months study. J Pakistan, Dent Assoc 2012;21:24-7.

12. Yip HK, Lam WT, Smales RJ. Surface roughness and weight loss of esthetic restorative materials related to fluoride release and uptake. $\mathrm{J}$ Clin Pediatr Dent. 1999 Summer;23(4):321-6.

13. García-Godoy F, García-Godoy A, García-Godoy F. Effect of a minute foam on the surface roughness, hardness, and micro morphology of high viscosity glass ionomer. J Dent Child (Chic). 2003 Jan-Apr;70(1):19-23.

14. Smith GE. Surface deterioration of glass ionomer cement during acid etching an sem evaluation. Oper Dent. 1988 Winter;13(1):3-7. 